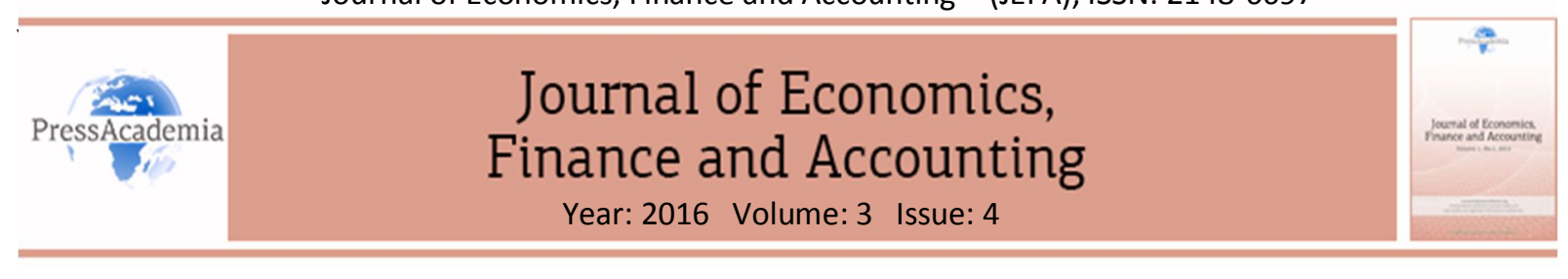

\title{
THE ANALYSIS OF FINANCIAL BETA BEHAVIOUR VIA PANEL QUANTILE REGRESSION APPROACH
}

\section{DOI: 10.17261/Pressacademia.2016.342}

Hakan Aygoren ${ }^{1}$, Umut Uyar ${ }^{2}$

${ }^{1}$ Pamukkale Üniversitesi, haygoren@pau.edu.tr

²Pamukkale Üniversitesi, uuyar@pau.edu.tr

\begin{abstract}
In finance theory, Market model has been a major issue for decades. Especially, it is used by most of the researchers to estimate financial beta coefficient. It is obvious that there are some weaknesses to use Ordinary Least Squares (OLS) for estimation of the market model. The coefficients estimated by OLS explain only for mid-point of distribution and the OLS estimator does not consider extreme values. Therefore, Quantile Regression technique provides considering outliers and a detailed report while estimating the market model. The aim of the study is investigating the differences of financial beta coefficients on different quantiles via panel quantile regression technique. For this purpose, daily stock returns which traded in Borsa Istanbul and New York Stock Exchange are used for 2011-2015 period. Findings show that financial beta coefficients change for different points of stock returns for both markets. It is clear that investors which regard differences of the financial beta coefficient on different quantiles prevent the possible strategic mistakes and losses. Besides, findings contain some important evidences about investor behaviors.
\end{abstract}

Keywords: Financial beta, market model, panel quantile regression

JEL Classification: C21, C23, D53, G12

\section{FINANSAL BETA DAVRANIŞININ PANEL KANTIL REGRESYON YÖNTEMI ILE INNCELENMESi}

\section{ÖZET}

Piyasa Modeli uzun yıllar boyunca finans teorisinde önemli bir rol oynamıs, özellikle finansal beta katsayısının tahmini amacıyla birçok araştırmacı tarafından analizlerde sıkıkla kullanıımıştır. Modelin tahmininde En Küçük Kareler Yöntemi'nin (EKK) kullanılmasının bir takım sakıncaları bulunmaktadır. EKK tahmincisi ile elde edilen sonuçlarda dağılımın sadece orta noktası için katsayılar hesaplanabilmekte ve uç değerleri dikkate almamaktadır. Bu nedenle, modelin kantil regresyon yaklaşımı ile tahmin edilmesi uç değerlerin de dikkate alındığı daha detaylı bir raporlama sağlamaktadır. Çalışmanın amacı, Kantil Regresyon tekniğini panel veriye uygulayarak, 2011-2015 dönemi için Borsa İstanbul ve New York Borsası'nda işlem görmüş hisselerin günlük getirileri ile dağııımın farklı noktaları için finansal beta katsayısında meydana gelen değişimleri araştırmaktadır. Bu amaçla yapılan analizler sonucunda, finansal beta katsayısııın her iki piyasada da farklı hisse senedi getiri noktalarında değiştiği tespit edilmiştir. Yatırımcıların farkılıaşan beta katsayılarını dikkate alarak yapacakları yatırımların stratejik hataların önüne geçeceği öngörülmüştür. Ayrıca, bulgularda yatırımcı psikolojisi hakkında da bir takım çıkarımlar yapılmıştır.

Anahtar Kelimeler: Finansal beta, piyasa modeli, panel kantil regresyon

JEL Sınıflandırması: C21, C23, D53, G12 


\section{GíRiş}

Gün geçtikçe küresel hale gelen finansal piyasalarda belirsizlik ortamındaki yatırım kararları daha da önemli bir hal almaktadır. Ancak, teknolojik gelişmelerle beraber yatırımcıların maruz kaldığı büyük oranda veri ve bilgi akışı geleneksel teorilerin ve matematiksel modellemelerin yetersiz kalmasına neden olmaktadır. Bu nedenle, finansal teorinin temellerini analiz edebilmek ve finansal kararlara ışık tutabilmek için daha hassas matematiksel araçlara ve ekonometrik modellere ihtiyaç duyulmaktadır. İhtiyacın bu şekilde gelişmesi, araştırmacıları son yıllarda piyasa davranışlarını daha detaylı ölçme ve değerlenme fonksiyonuna sahip modeller geliştirmesini sağlamıştır. Modern portföy yaklaşımının 1952 yılında Harry Markowitz tarafından ortaya atılmasından sonra William Sharpe ve John Lintner 'ın katkıları ile geliştirilen Sermaye Varlıklarını Fiyatlama Modeli (CAPM) finans teorisi açısından bir dönüm noktası oluşturmuştur. Özellikle CAPM modeli ile kaotik bir ortam olan finansal piyasalar, ilk defa ekonometrik bir modelle açıklanmıştır. CAPM'in geliştirme aşamalarından birisi olan ve yine William Sharpe (1963) tarafından ortaya atılan Piyasa Modeli de özellikle uygulama ve yorumlama kolaylığından ötürü finansal araştırmalarda önemli bir kullanım alanına sahip olmuştur.

Piyasa Modeli ve CAPM uzun yıllar boyunca finans teorisinde önemli bir rol oynamış, birçok araştırmacı ya da yatırımcı tarafından analizlerde sıklıkla kullanılmıştır. Modeller, basit ve uygulanabilir olma özellikleri nedeniyle oldukça revaçta olmasına rağmen kendi içerisinde bir takım sorunlar da barındırmaktadır. Bu sorunlardan birincisi, modellerin tahmin sonuçlarında çelişkili bulgular elde edilmesi ve bir takım düzeltmelere ihtiyaç duyulmasıdır (Chang vd., 2011). İkinci olarak da, özellikle CAPM'in bir ortalama-varyans verimliliği üzerine kurulduğu ve elde edilen çıktıların etkin ve dengede olan bir piyasada oluştuğu varsayımıdır. Gerçek piyasa koşulları altında zaman zaman istatistiksel olarak anlamsız sonuçlar verebilmektedir. Bir diğer sorun ise, hisse senedi getirileri ile piyasa getirisi ya da piyasa sistematik risk primi arasında doğrusal bir ilişki kurmasıdır. Getirileri açıklamada sadece tek bir değişken kullanıyor olması modelin aldığı eleştirilerin başında gelmektedir. Doğrusallık ve tek değişken problemini ortadan kaldırmak için kendisinden sonra da modeller geliştirilmeye devam edilmiştir.

Araştırmacılar tarafından sıklıkla kullanılan modellerin bahsi geçen kısıtları altında, parçalı bir tahmin tekniğinin uygulanması yeni ve farklı bir araştırma alanı oluşturmaktadır. Basit regresyon modeli tahmininde kullanılan tahmincilerden birisi olan En Küçük Kareler Yöntemi (EKK), bahsi geçen finansal modellerin tahmini için kullanılmaktadır. EKK tahmincisi ile elde edilen sonuçlarda dağılımın sadece orta noktası için katsayılar hesaplanabilmektedir. Dağılımda yer alan uç değerler, EKK tahmincisi ile yapılan tahminlerde göz ardı edilmektedir. Koenker ve Bassett (1978) tarafından geliştirilen Kantil Regresyon tekniği, dağılımı araştırmacının belirlediği parçalara bölerek, uç değerleri de dikkate alan birden fazla katsayı elde edilmesini sağlamaktadır. Konunun daha net ifade edilmesi açısından Şekil 1'de yer alan grafik gösterilmektedir.

Yatay eksende belirlenen risk düzeylerinin, dikey eksende ise beklenen getirilerin yer aldığı Şekil 1'de yer alan dağılım grafiğinde “.50” ile gösterilen doğru EKK yöntemi ile tahmin edilen Menkul Değer Piyasası Doğrusu'nu temsil etmektedir. Az önce de anlatıldığı üzere EKK ile tahmin edilen regresyon doğrusu dağılımın orta bölgesinden geçmekte ve uç değerleri dikkate almamaktadır. Ancak dağılımda en yüksek getiriye sahip “.75"lik dilimde yer alan değerler dikkate alınarak tahmin edilen Kantil Regresyon sonucunda elde edilen doğrunun eğimi dolaysıyla finansal beta katsayısı EKK tahmininden farklı bir sonuç vermektedir. Diğer yandan dağılımda en düşük getiriye sahip “.25”lik dilimde yer alan değerler dikkate alınarak tahmin edilen Kantil Regresyon sonucunda da farklı bir finansal beta katsayısı ile karşılaşılmaktadır. Kantil regresyon yöntemi ile yapılan analizler sonucunda, yüksek getirili hisse senetleri için farklı, düşük getirili hisse senetleri için farklı piyasa doğruları ve finansal beta katsayıları olduğu bilgisi yatırımcılara ve diğer piyasa çevrelerine sağlanmış olmaktadır. 
Şekil 1: Kantil Regresyon Grafiği

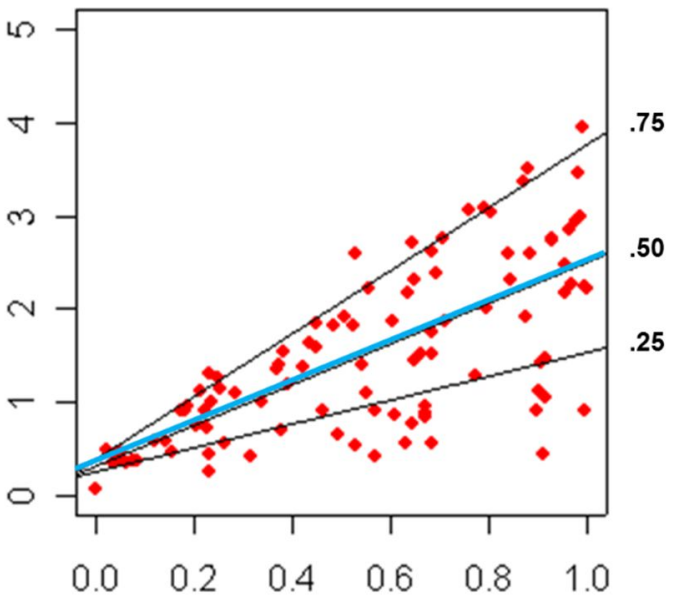

Bu çalışmanın amacı, Kantil Regresyon tekniğini panel veriye uygulayarak, 2011-2015 dönemi için Borsa İstanbul ve New York Borsası'nda işlem görmüş hisselerin getirileri ile dağılımın farklı noktaları için finansal beta katsayısında meydana gelen değişimleri araştırmak ve varsa tespit edilen finansal beta değişimlerini yatırımcı davranışları açısından değerlendirmektir. Bu amaçla, Borsa İstanbul Ulusal 100 endeksinde işlem gören 82 hisse senedine ait 1259 günlük getiri verisi, New York Borsası S\&P100 Endeksinde işlem gören 93 hisse senedine ait 1257 günlük getiri verisi kullanılacaktır. Analizlerden elde edilecek bulgular, gelişmekte olan ve gelişmiş piyasa örnekleri açısından tartışılacaktır.

Çalışmanın ikinci bölümünde konu ile ilgili literatür özeti sunulacak, üçüncü bölümde veri ve metodoloji hakkında bilgi verilecektir. Analiz bulgularının tartışıldığı bölümden sonra sonuç ve değerlendirmelere yer verilecektir.

\section{LITERATÜR ARAŞTIRMASI}

Yatırım kararlarının verilmesi konusunda yatırımcılara bilgi sağlaması açısından yapılan araştırmalar uzun yıllardır devam etmektedir. Finans teorisi olarak adlandırılabilecek çalışmaların temeli 1952 yılında Harry Markowitz'in "Portföy Seçimi" adlı makalesine uzanmaktadır. İktisadi bakış açısının geleneksel portföy yaklaşımına farklı bir bakış açısı getiren Markowitz (1952) çalışmasında, sadece portföy çeşitlendirilmesine gidilerek riskin azaltılamayacağını, portföyde yer alan menkul kıymetler arasındaki ilişkinin yönünün ve derecesinin de riskin azaltılması yönünde etkili olduğunu "Ortalama - Varyans Modeli" ile ortaya koymaktadır. Markowitz'in çalışmaları finans teorisi açısından bir başlangıç noktası oluşturmuş ve birçok araştırması piyasa dinamiklerini anlamaya ve açıklamaya yönelik modeller geliştirme çabası içerisine girmiştir (Tobin, 1958; CohenPogue, 1967; Elton-Gruber, 1973; Rosenberg, 1974). Literatürde bu alanda ön plana çıkan bir diğer çalışma da 1963 yılında William Sharpe'ın "Portföy Analizi için Yalınlaştırılmış Bir Model” isimli çalışmasıdır. Sharpe (1963), Markowitz'in 1952'deki makalesinde ortaya attığı etkin sınırın bir faktör modeli ile hesaplanabileceğini göstermiştir. Daha sonra Sharpe (1964), Lintner (1965) ve Mossin'in (1966) çalışmaları sonucunda modelin hem matematiksel, hem de mantıksal bir uzantısı olan Sermaye Varlıkları Fiyatlandırma Modeli (CAPM) ortaya çıkmıştır. CAPM, getirinin değişkenliğinin iki bileşenini, piyasanın gidişatına bağlı sistematik risk, menkul kıymetin kendine özel olanına ise sistematik olmayan risk olarak adlandırmıştır. Sistematik risk, tüm piyasayı etkilediği varsayımından yola çıkılarak bu piyasadan oluşturulacak bir portföyün de aynı riski taşıdığı ve dolayısıyla çeşitlendirme ile tamamen ortadan kaldırılamayan riski ifade etmektedir. Diğer taraftan menkul kıymetin kendine özel riskinin ise çeşitlendirme ile giderilebileceği belirtilmektedir (Irmak ve Çetin, 2009).

CAPM, basit ve uygulanabilir olma özellikleri nedeniyle uzun zaman boyunca birçok araştırmacı tarafından kullanılmıştır. Zamanla temel bir model haline gelen CAPM'e farklı değişkenler eklenerek farklı amaçlarla piyasa analiz edilmeye ve işleyişi ortaya konulmaya çalışılmıştır (Ross, 1976; Roll \& Ross, 1980; Fama \& French, 1996). Diğer bir yandan CAPM'in model değişkenlerinde bir değişiklik yaratmadan farklı tekniklerle piyasa işleyişi 
araştıran çalışmalar da bulunmaktadır. Özellikle parçalı bir tahmin tekniğinin CAPM üzerine uygulanması modele yeni ve farklı bir yorum kazandırmıştır. Bu alanda yapılan ilk çalışmalardan biri Barnes ve Hughes'in (2002) araştırmasıdır. Yazarlar 1093 firma kullanarak yaptıkları yatay kesit kantil regresyon tahmini sonucunda finansal beta katsayısının, teklif-satış fiyatı değişkeninin ve logaritmik aktif büyüklüğünün, firma getiri dağılımının sırasıyla $\% 10, \% 30, \% 50, \% 70$ ve $\% 90$ 'ık dilimlerinde farklı değerler aldığını göstermişlerdir. Diğer bir ifade ile getirisi düşük ve yüksek olan firmaların finansal beta katsayılarının farklı oluştuğunu ortaya koymuşlardır. Ma ve Pohlman'ın (2008) çalışmaları katil regresyon tekniğinin diğer finansal verilerde de uygulanabileceğini göstermiştir. Ocak 1990 - Haziran 2004 dönemlerinde aylık olarak Russell1000, S\&P500, ve S\&P400 endekslerine işlem gören 1100 hisse senedinin kullanıldığı çalışmada, firmalara ait farklı finansal göstergeler ile modeller kurulmuştur. Bu göstergeler içerisinde, Defter Değeri Piyasa Değeri Oranı, Gelir/Fiyat Oranı, Borç Oranı, Kar Yedekleri Aktif Toplam Oranı, Yükümlülüklerin Piyasa Fiyatına Oranı ve firmaların Z-Score değişkeni kullanılmıştır. Örneklemde yer alan firmalar $\% 20, \% 40, \% 60$ ve $\% 80^{\prime}$ lik kantillere ayrılmıştır. Çalışma bulgularında yazarlar, firmaların sadece risk açısından değil, getiri açııından da katiller arasında farklı davranışlar sergilediği sonucuna ulaşmışlardır. Allen ve Singh (2009) çalışmalarında finansal piyasa hareketlerinin kriz ortamlarında açıklamak için EKK tahmincisinin yetersiz olduğunu vurgulamaktadır. Özellikle Global Finansal Kriz sırasında oluşan etkileri ve piyasa enstrümanlarının davranışlarını kantil regresyon tekniğinin daha gerçekçi ortaya koyduğunu ifade edilmektedir. Bu amaçla Ocak 2005 - Aralık 2008 döneminde Dow Jones İmalat Sektöründe faaliyet gösteren 30 firma üzerinde Fama-French üç faktör modelini kullanarak kantil regresyon tahmini gerçekleştirmişlerdir. Tahminlerini \%5, \%25, \%50, \%75 ve\%95'lik kantillere uygulayan yazarlar, kantil regresyon çıktılarının geleneksel EKK çıktılarına göre çok daha etkin sonuç verdiğini ve hatta gelecek çalışmalarda kullanılmasını önermişlerdir. Allen vd.'nin (2009) çalışmasında ise Avustralya piyasasında Global Finansal Kriz sırasında CAMP modeli kullanılarak kantil regresyon ve EKK regresyonu karşılaştırması yapılmıştır. Yazarlar, özellikle kriz dönemlerinde piyasada uç değerlerin ciddi oranda arttığını ve EKK yönteminin bu değerleri dikkate almadan yaptığı CAPM tahminlerinin yatırımcılar açııından etkin olmadığını vurgulamaktadır. ASX 50 endeksinde yer alan hisse senetlerine yapılan uygulama sonucunda kantil regresyonun birçok açısından EKK yöntemine göre üstün olduğu sonucuna ulaşılmıştır. Li, Sun ve Zou (2009) ise çalışmalarında Çin Sermaye Piyasası'nda işlem gören 643 finansal olmayan firma kullanmışlar ve devlet hissedarlı̆̆ı ile firma finansal performansı arasındaki ilişkiyi incelemişlerdir. Yapılan analizlerde kantil regresyon ile EKK karşılaştırması yapılmış ve kantil regresyonun EKK'ya göre çok daha dirençli ve etkin raporlama yaptı̆̆ı sonucuna ulaşılmıştır. Konu ile ilgili yapılan son çalışmalardan birisi de Chang, Hung ve Nieh'in (2011) çalışmalarıdır. Araştırmacılar, sistematik risk ile getiri arasındaki ilişki EKK ve kantil regresyon kullanarak incelemişlerdir. Uygulama sonuçlarına göre EKK kullanılarak yapılan tahminlerde sistematik risk ile getiri arasında istatistiksel olarak anlamlı ve pozitif bir ilişki tespit edilmiştir. Ancak tahminler kantil regresyon ile yapıldığında düşük kantillerde pozitif ilişki istatistiksel olarak anlamsızken, yüksek kantillerde yine istatistiksel olarak anlamlıdır. Yazarlar bu sonuçlara göre sistematik risk ile getiri arasındaki pozitif ilişkinin her zaman sürdürülebilir olmadığını vurgulamaktadır.

Literatür araştırmasından çıkarılabilecek sonuç, finansal piyasa ilişkilerini incelemede geleneksel EKK tahmincisi ile yapılan model tahminleri her zaman etkin, geçerli ve doğru sonuç vermeyebilmektedir. Bu nedenle, yapılacak tahminlerin kantil regresyon tekniği ile incelenmesi, hem raporlamada bilgi zenginliği hem de detay ilişki incelemesine olanak sağlamaktadır.

\section{VERI VE YÖNTEM}

Çalışmanın araştırma aşamasında kullanılan model, Sharpe (1963) tarfından geliştirilen Piyasa Modeli'nin ${ }^{1}$ panel veri analizi formudur. Model Eşitlik 1'de ve bileşenleri de devamında açıklanmaktadır.

$R_{i t}=\alpha_{i t}+\beta_{i t} R_{m t}+\varepsilon_{i t}$

Modelde;

$R_{i t} \quad:$ t zamandaki i hisse senedinin getiri serisini

$R_{m t} \quad$ : Piyasa portföyü getiri serisini

\footnotetext{
${ }^{1}$ Piyasa Modeli diğer bir adı "Tek Indeks Modeli” olarak da bilinmektedir.
} 
$\alpha_{i t} \quad$ : Sabit etkileri

$\beta_{i t} \quad$ : Model eğim katsayısını (Finansal Beta)

$\varepsilon_{i t} \quad$ : Hata terimini

ifade etmektedir.

Kantil regresyon tekniği, Koenker and Bassett (1978) 'in çalışmalarından sonra ampirik çalışmalarda geniş uygulama alanı bulmuştur. Kantil regresyon ile EKK arasındaki temel farklılık, EKK'nın tüm gözlem değerlerine eşit ağırlık vermesi, buna karşııı kantil regresyon tekniğinin bağımlı değişkenin koşullu dağılımındaki farklı dilimler için farklı ağırlıklandırmalar yapmasıdır. Böylece EKK'ın dikkate almadığı hisse senedi getirilerinin uç değerleri için de piyasa modelleri kurulması mümkün olmaktadır. Bu şekilde farklı getiri düzeylerinde piyasa getirisinin etkisinin farklılaşması incelenebilmekte ve daha detaylı sonuç alınabilmesi sağlanmaktadır.

Çalışmada kantil regresyon tekniğinin panel veriye uygulanması gereği Eşitlik 1'de yer alan modelin her iki borsa örneği açısından aşağıdaki gibi düzenlenmesi gerekmektedir.

$R_{i t}\left(\tau \mid X_{i t}\right)=\beta_{1}(\tau)\left(R_{\text {BIST100_t }}\right)+\alpha_{i}+u_{i t}$
$R_{i t}\left(\tau \mid X_{i t}\right)=\beta_{2}(\tau)\left(R_{S \& P 100_{-} t}\right)+\gamma_{i}+e_{i t}$

Modellerde,

$\tau \quad$ : Araştırmacı tarafından belirlenen kantil değerlerini

$X_{i t} \quad$ : Açıklayıcı değişkenleri

$\alpha_{i}, \gamma_{i} \quad$ : Sabit etkileri

$u_{i t}, e_{i t}:$ Hata terimlerini

ifade etmektedir.

Analizlerde kullanılacak olan veri seti 04.01.2011 - 31.12.2015 periyodunda meydana gelen günlük getirileri içermektedir ve Bloomberg Terminal aracılığı ile elde edilmiştir. Araştırma Borsa İstanbul Ulusal-100 endeksinde ilgili dönemde yer alan 82 firmaya ait hisse senedini ve Ulusal-100 Endeksini ve New York Borsası S\&P100 Endeksinde ilgili dönemde işlem gören 93 hisse senedini ve S\&P100 Endeksini kapsamaktadır. Bu açıdan Borsa İstanbul için yapılacak tahminler gelişmekte olan bir piyasayı temsil ederken, New York Borsası için yapılan tahminler gelişmiş bir piyasayı temsil etmektedir. Yapılacak iki ayrı tahminde ilgili dönemde Borsa İstanbul için 1259 getiri gözlemi içerirken, New York Borsası 1257 getiri gözlemi içermektedir. Gözlem sayılarındaki farklılık tatil günlerinin farklı olmasından kaynaklanmaktadır.

\section{BULGULARIN YORUMU}

Araştırmanın bulguları bölümünde, bulguların yorumuna geçmeden önce verilerin tanımlayıcı istatistiklerine yer verilmektedir. Tablo 1'de modellerde kullanılan değişkenlerin tanımlayıcı istatistikler, Şekil 2'de ise değişkenlerin dağılım grafikleri yer almaktadır.

Tablo 1: Tanımlayıcı İstatistikler

\begin{tabular}{|l|r|r|r|r|}
\hline & $\begin{array}{r}\text { BiST100 } \\
\text { (82 Hisse) }\end{array}$ & $\begin{array}{r}\text { BisT100 } \\
\text { Endeks }\end{array}$ & $\begin{array}{r}\text { S\&P100 } \\
\text { (93 Hisse) }\end{array}$ & $\begin{array}{r}\text { S\&P100 } \\
\text { Endeks }\end{array}$ \\
\hline Ortalama & 0.000233 & $4.70 \mathrm{E}-05$ & 0.000434 & 0.000377 \\
\hline Medyan & 0.000000 & 0.000714 & 0.000481 & 0.000544 \\
\hline Maksimum & 0.429038 & 0.062379 & 0.166268 & 0.046317 \\
\hline Minimum & -0.222148 & -0.110638 & -0.249491 & -0.068958 \\
\hline Standart Sapma & 0.024335 & 0.014989 & 0.014825 & 0.009752 \\
\hline Kayıklık & 0.241659 & -0.565627 & -0.216843 & -0.505199 \\
\hline Basıklık & 12.97195 & 7.026567 & 11.59724 & 7.906659 \\
\hline Gözlem Sayısı & 103238 & 103238 & 116901 & 116901 \\
\hline
\end{tabular}


Şekil 2: Değişkenlerin Dağılım Grafikleri
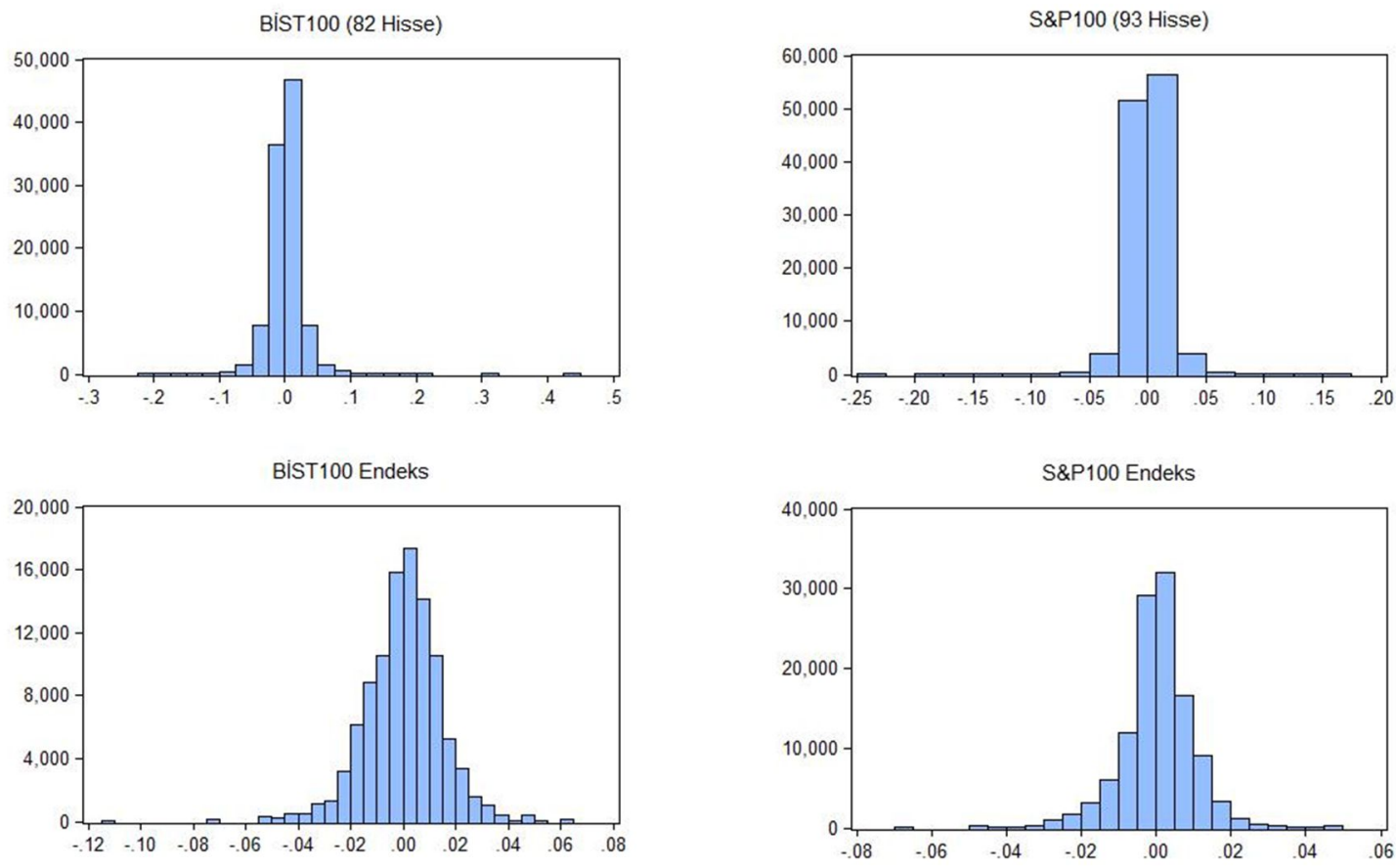

Modellerin tahmini aşamasına geçmeden önce panel birim kök testlerinin yapılması gerekmektedir. Panel veri analizinde iki nesil birim kök testi bulunmaktadır. Birinci nesil birim kök testleri tarihsel sıralamada ilk geliştirilen testler olmakla beraber, modelde yatay kesit bağımlılı̆ının olmadığı varsayımı altında uygulanmaktadır. Ancak güvenilir sonuçlar elde edilebilmesi için modelde yatay kesit bağımlılığının incelenmesi gerekmektedir. Yatay kesit bağımlılığı olması durumunda ise ikinci nesil panel birim kök testlerinin uygulanması gerekmektedir. Bu nedenle modellerde Breusch-Pagan LM test istatistiği ve Pesaran CD test istatistiği hesaplanmıştır. Yatay kesit bağımlılık testleri sonuçları Tablo 2'de gösterilmektedir.

Tablo 2: Yatay Kesit Bağımlılı̆̆ı Test İstatistikleri

\begin{tabular}{|l|c|c|c|c|}
\hline \multirow{2}{*}{ Modeller } & \multicolumn{2}{|l|}{ Breusch-Pagan LM testi } & \multicolumn{2}{l|}{ Pesaran CD testi } \\
\hline & Test İstatistiği & Olasılık Değeri & Test İstatistiği & Olasılık Değeri \\
\hline Eşitlik 2 (Borsa İstanbul) & 668.2436 & 0.0000 & 63.9314 & 0.0000 \\
\hline Eşitlik 3 (New York Borsası) & 1038.6781 & 0.0000 & 3.8407 & 0.0001 \\
\hline
\end{tabular}

Tablo 2'de yer alan Breusch-Pagan LM ve Pesaran CD yatay kesit bağımlılığı test istatistikleri incelendiği takdirde, iki modelde de yatay kesit bağımlılığının olduğu sonucuna ulaşılmıştır. Bu durumda güvenilir sonuçların elde edilmesi için panel birim kök sınamalarında ikinci nesil panel birim kök testlerinin kullanılması gerekmektedir.

Bu amaçla iki farklı testten yararlanılmıştır; Taylor ve Sarno (1998) tarafından geliştirilen Multivariate Augmented Dickey-Fuller (MADF) testi ve Pesaran (2007) tarafından geliştirilen The Individual Cross-Sectionally Augmented Dickey-Fuller (CADF) testi. MADF testi sıfır hipotezi "panel verideki tüm zaman serileri birinci mertebeden durağan değildir” olarak ifade edilmektedir. MADF testi sonuçları Tablo 3'te gösterilmektedir. 
Tablo 3: ikinci Nesil MADF Birim Kök Test İstatistikleri

\begin{tabular}{|l|c|c|}
\hline Seriler & Kritik Değer (\%5) & Olasılık Değeri \\
\hline BisT100 (82 Hisse) & 11.683 & 0.0000 \\
\hline S\&P100 (93 Hisse) & 11.684 & 0.0000 \\
\hline
\end{tabular}

CADF testi için oluşturulan sıfır hipotezi de "panel verideki tüm zaman serileri birinci mertebeden birim kök içerir" şeklinde kurulmuştur. CADF test istatistikleri de Tablo 4'te gösterilmektedir

Tablo 4: íkinci Nesil CADF Birim Kök Test İstatistikleri

\begin{tabular}{|l|c|c|c|c|}
\hline Seriler & CIPS İstatistiği $^{\mathbf{3}}$ & Kritik Değer (\%1) & Kritik Değer (\%5) $^{\text {Kritik Değer (\%10) }}$ \\
\hline $\begin{array}{l}\text { BisT100 Hisse } \\
\text { Sabitli }\end{array}$ & -25.243 & -2.18 & -2.08 & -2.03 \\
\hline $\begin{array}{l}\text { BisT100 Hisse } \\
\text { Sabitli ve Trendli }\end{array}$ & -25.261 & -2.18 & -2.08 & -2.03 \\
\hline $\begin{array}{l}\text { S\&P100 Hisse } \\
\text { Sabitli }\end{array}$ & -25.544 & -2.18 & -2.08 & -2.03 \\
\hline $\begin{array}{l}\text { S\&P100 Hisse } \\
\text { Sabitli ve Trendli }\end{array}$ & -25.564 & -2.18 & -2.08 & -2.03 \\
\hline
\end{tabular}

Maksimum gecikme uzunluğu 2 olarak alınmış ve optimal gecikme uzunlukları, Schwarz bilgi kriterine göre belirlenmiştir. Kritik değerler: Pesaran (2007), Tablo II(b), s:280

Tablo 3 ve 4'te yer alan test istatistikleri incelendiği takdirde, MADF ve CADF yatay kesit bağımlılığını dikkate alan ikinci nesil panel birim kök testleri sonuçlarına göre tüm serilerin durağan olduğu sonucuna ulaşılmıştır. Durağanlık incelemesinin ardından modellerin tahmini aşamasına geçilebilmektedir.

Model tahmini aşamasında Eşitlik 2 ve Eşitlik 3'te yer alan modeller, Koenker (2004) tarafından geliştirilen Panel Kantil Regresyon tekniği kullanılarak tahmin edilmiştir. Tahminlerde hisse senedi getiri dağılımının \%25, \%50 ve \%75'lik kantilleri için katsayılar hesaplanmıştır. Eşitlik 2'de yer alan ve Borsa İstanbul için yapılan Panel Kantil Regresyon tahmin sonuçları Tablo 5'te gösterilmektedir.

Tablo 5: Eşitlik 3 Panel Kantil Regresyon tahmin sonuçları (Borsa İstanbul)

\begin{tabular}{|l|c|c|c|c|c|}
\hline Kantil $(\boldsymbol{\tau})$ & Parametreler & Katsayılar & $\begin{array}{c}\text { Standart } \\
\text { Hata }\end{array}$ & t-istatistiği & $\begin{array}{c}\text { Olasılık } \\
\text { Değeri }\end{array}$ \\
\hline \multirow{2}{*}{$\% 25$} & $\mathrm{~A}$ & -0.01023 & 0.00018 & -58.25506 & 0.0000 \\
\cline { 2 - 6 } & $\beta_{1}$ & 0.67623 & 0.04087 & 16.54579 & 0.0000 \\
\hline \multirow{2}{*}{$\% 50$} & $\alpha$ & -0.00064 & 0.00005 & -11.90031 & 0.0000 \\
\cline { 2 - 6 }$\% 75$ & $\beta_{1}$ & 0.60619 & 0.04493 & 13.49272 & 0.0000 \\
\cline { 2 - 6 } & $\alpha$ & 0.00959 & 0.00024 & 39.44175 & 0.0000 \\
\hline
\end{tabular}

Eşitlik 3'de yer alan ve Borsa İstanbul için yapılan Panel Kantil Regresyon tahmin sonuçları Tablo 6'da gösterilmektedir.

\footnotetext{
${ }^{2}$ BIST100 ve S\&P100 Endeks serileri her bir firma için panel içerisinde tekrarlayan bir seri oluşturduğu için panel birim kök sınamasına tabi tutulmamıştır.

${ }^{3}$ CIPS istatistiği, CADF istatistiklerinin ortalamasıdır (Pesaran, 2007).
} 
Tablo 6: Eşitlik 4 Panel Kantil Regresyon tahmin sonuçları (New York Borsası)

\begin{tabular}{|l|c|c|c|c|c|}
\hline Kantil $(\boldsymbol{\tau})$ & Parametreler & Katsayılar & $\begin{array}{c}\text { Standart } \\
\text { Hata }\end{array}$ & t-istatistiği & $\begin{array}{c}\text { Olasılık } \\
\text { Değeri }\end{array}$ \\
\hline \multirow{2}{*}{$\% 25$} & $\gamma$ & -0.00532 & 0.00012 & -42.73073 & 0.0000 \\
\cline { 2 - 6 } & $\beta_{2}$ & 0.96556 & 0.02688 & 35.91503 & 0.0000 \\
\hline \multirow{2}{*}{$\% 50$} & $\gamma$ & -0.00005 & 0.00002 & -2.645830 & 0.0082 \\
\cline { 2 - 6 } & $\beta_{2}$ & 0.95407 & 0.02491 & 38.30050 & 0.0000 \\
\hline \multirow{2}{*}{$\% 75$} & $\gamma$ & 0.00540 & 0.00012 & 45.44938 & 0.0000 \\
\cline { 2 - 6 } & $\beta_{2}$ & 0.95965 & 0.02680 & 35.80783 & 0.0000 \\
\hline
\end{tabular}

Çalışmanın amacı doğrultusunda finansal betanın kantiller arasında nasıl farklılaştığının tespiti için her iki piyasa için yapılan katsayı tahminleri Şekil 3’te özetlenmiştir.

Şekil 3: Kantillere göre Finansal Beta Değişim Grafikleri
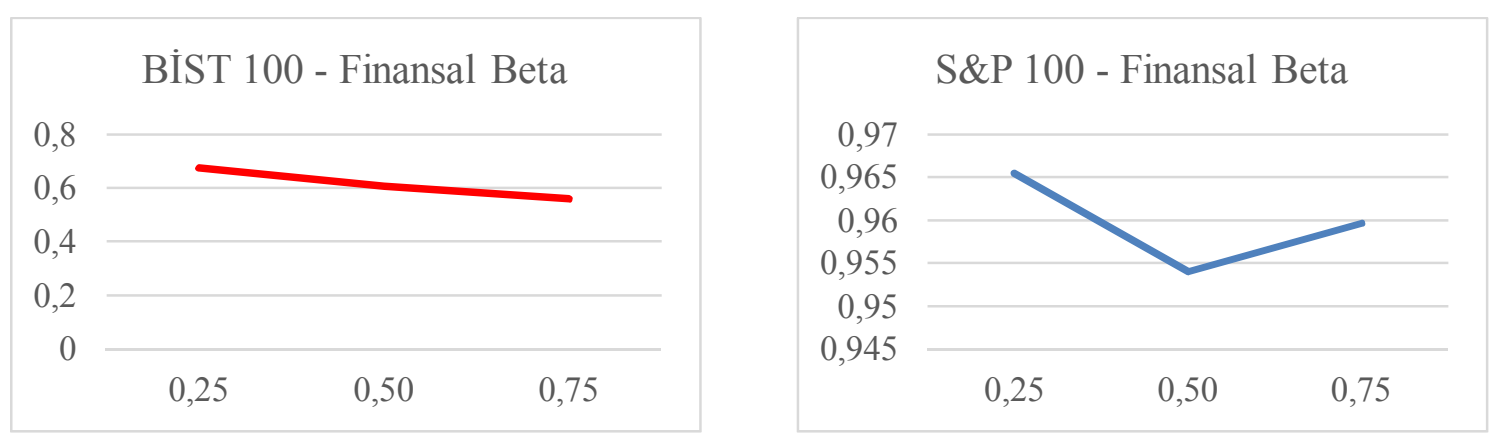

Tablo 5'te yer alan piyasa modelinden elde edilen sonuçlar değerlendirildiğinde, Borsa İstanbul açısından piyasa modeli sabitinin ve finansal beta katsayısı farklı getiri seviyeleri için farklı sonuçlar verdiği görülmektedir. Finansal beta katsayısı \%25'lik kantilde 0.6762 'lik bir değer alırken, \%50'lik kantilde 0.6061 ve \%75'lik kantilde 0.5604 şeklinde hesaplanmıştır. Şekil 3'te yer alan grafik ile beraber değerlendirildiğinde, incelenen dönem için finansal beta katsayısı, hisse senetlerinin yüksek getiri seviyelerinde, düşük getiri seviyelerine göre daha düşük bir değer aldığı görülmektedir. Analizler çalışmanın amacına uygun olarak dağıımın farklı noktaları için finansal beta katsayısında değişimler meydana geldiğini göstermektedir. Finansal beta katsayısının piyasa getirilerinin yüksek olduğu iyimser dönemlere göre düşük olduğu kötümser olarak adlandırılabilecek dönemlerde farklılaşması Kahneman ve Tversky'nin 1979 tarihli "Beklenti Teorisi” çalışmaları ile açıklanabilmektedir." Beklenti teorisine göre, yatırımcılar piyasada yatırım kararı verirken rasyonel hareketler içerisinde bulunmamaktadır. Yatırımcılar, kesin kazanç seçeneklerini, daha yüksek oranda olasılıklı kazanç seçeneklerine karşı tercih ederken; olasılıkıı kayıp seçeneklerini, daha düşük kesin kayıp seçeneklerine karşı tercih etmektedir. Açıklanan teori ışığında sonuçlar değerlendirilecek olursa Borsa İstanbul açısından, yüksek getiri dönemlerinde yatırımcılar iyimser hava nedeniyle kazançlara odaklanmakta ve fiyatlamalarda sistematik riski olması gereken seviyeden daha düşük belirlemektedir. Bu nedenle \%75'lik kantilde finansal beta orta noktaya göre azalmaktadır. Aksi durumda ise, yatırımcılar kötümser ortamda getirilere değil sistematik riske odaklanmakta ve finansal beta katsayısı diğer kantillere göre daha yüksek seviyede öngörmektedir.

Tablo 6'da yer alan ve New York Borsası için tahmin edilen piyasa modelinden elde edilen sonuçlar incelendiğinde, Borsa İstanbul için kurulan modelde olduğu gibi sabitinin ve finansal beta katsayısı farklı getiri seviyeleri için farklı sonuçlar verdiği gözlenmektedir. New York Borsası için finansal beta katsayısı \%25'lik kantilde 0.9656 , \%50'lik kantilde 0.9541 ve $\% 75^{\prime}$ lik kantilde 0.9596 'lik bir değer almıştır. Borsa İstanbul ile

\footnotetext{
${ }^{4}$ Ayrıntılı bilgi için bkz: Kahneman ve Tversky (1979), Sharpe vd. (1999: 146-147), Küden, M. (2014).
} 
karşılaştıııldığında New York Borsası'nda piyasa getirisi ile hisse senedi getirileri arasında ciddi oranda yüksek bir ilişki bulunmaktadır. Şekil 3'te yer alan grafik ile beraber değerlendirildiğinde, incelenen dönem için finansal beta katsayısının, EKK tahmincisinden elde edilen \%50'lik kantile göre düşük ve yüksek getiri seviyelerinde daha yüksek olduğu görülmektedir. Bu sonuç, EKK tahmincisi ile elde edilen katsayıların hisse senetlerinin düşük ve yüksek getiri dönemlerinde farklılaştığını ve geçerliliğini kaybettiğini açıkça göstermektedir. Gelişmiş borsa temsili olarak çalışmaya dahil edilen S\&P100 endeksinde kantiller arasındaki finansal beta farkılıaşması ise Von Neuman ve Morgenstern'ın 1944 tarihli "Oyunlar Teorisi ve iktisadi Davranış" adlı eserlerinde geliştirdikleri "Beklenen Değer Hipotezi", ve Beklenti Teorisi kullanılarak açıklanabilmektedir. ${ }^{5}$ Beklenen Değer modeli iktisatta ve finansta kestirimci ve pozitivist olarak görülmektedir. Pozitivist bakış açısında, aksiyomların gerçekçiliğinin önemi bulunmamakta ve oyuncu açısından önemli olanın, modellerin daha kesin tahminler ortaya koyup koymadığı durumlar olmaktadır (Schoemaker, 1982). Bu açıdan hipotez yorumlandığında rasyonel yatırımcılar, piyasada beklenen değeri elde ettikleri sürece riske odaklanmamakta ve beklenti teorisindeki iyimser durumu sergilemektedir. New York Borsası için tahmin edilen model sonuçları açıklanan hipotez ve teori açsından değerlendirildiğinde yatıımcıların, getirilerin beklenen değerin dışında çıktığı düşük ve yüksek kantillerde sistemik riske odaklandığı ve dolayısıyla finansal betada artış meydana geldiği görülmektedir. Beklenen değerin gerçekleşmesi yani \%50'lik kantilde ise iyimser havanın oluştuğu ve yatırımcıların sistematik riske olan hassasiyetlerinin azaldığı tespit edilmektedir.

Bulgular, gelişmekte olan ve gelişmiş piyasa örnekleri açısından tartışılacak olursa; Borsa İstanbul ve New York Borsası arasında finansal beta seviyesi açısından açık bir farklılık bulunmaktadır. Panel verinin kullanıldığı analizlerde New York Borsası gelişmiş piyasa örneğini temsil etmekte ve tüm kantillerde finansal beta katsayısının bire yakın hesaplanması bu yargıyı doğrulamaktadır. Piyasa modeline göre piyasada faaliyet gösteren hisse senetleri piyasa endeksi ile neredeyse mükemmel bir uyum içerisinde hareket etmektedir. Çalışmanın amacı doğrultusunda yapılan panel kantil regresyon tahminlerine göre ise, EKK tahmincisi ile elde edilen katsayılara göre düşük ve yüksek getiri dönemlerinde daha yüksek finansal beta katsayıları hesaplanmıştır. Elde edilen bu bulgular, yatırımcıların EKK tahmincisine göre hareket etmesi durumunda stratejik hatalarla ve kayıplarla karşılaşabileceğini göstermektedir. Analizlerde Borsa İstanbul ise gelişmekte olan bir piyasayı temsil etmektedir. Finansal beta katsayısının New York Borsası'ndan elde edilen sonuçlara göre daha düşük olması da bu önermeyi desteklemektedir. Finansal beta katsayııının tüm kantillerde birden uzak kalması, borsa dinamikleri içerisinde yatırımcıların yatııım kararlarını verirken başka değişkenlerden etkilenebildiğini ve piyasada asimetrik bilgi durumunun olabileceğini göstermektedir. EKK tahmincisi ile elde edilen finansal beta katsayısı yüksek getiri dönemlerinde düşmekte, düşük getiri dönemlerinde ise yükselmektedir. İki piyasada kantiller açısından elde edilen bu farklı sonuçlar, Borsa istanbul'da beklenti teorisine göre yatırımcı psikolojisinden daha şiddetli etkilenen sığ bir piyasa oluşturulduğunu; New York Borsası'nda ise gözlemlenen rasyonel hareketlerin daha derin bir piyasa oluşturulduğunu gösterebilir. Ayrıca, yatırımcıların EKK tahmincisinden elde edilen katsayılara göre hareket etmeleri durumunda stratejik hatalarla karşı karşıya kalabileceğini de vurgulamaktadır.

\section{SONUÇ}

Finans literatüründe bir dönüm noktası olan ve William Sharpe'ın katkıları ile geliştirilen Piyasa Modeli, uzun yıllar boyunca birçok araştırmacı tarafından sıkıkla kullanıımışı̆. Özellikle piyasa getirisi ile hisse senedi getirileri arasındaki ilişkinin göstergesi olan finansal beta katsayısının hesaplanmasındaki uygulanabilirlik ve kolaylık açısından finans literatüründe önemli bir yer oluşturmaktadır. Araştırmacılar, bir basit regresyon olan modelin uygulama aşamasında genellikle En Küçük Kareler Yöntemi (EKK) kullanmaktadır. Ancak EKK tahmincisi sonuçlarında dağılımın sadece orta noktası için katsayılar hesaplanabilmekte ve uç değerleri göz ardı etmektedir. Sermaye piyasaları üzerine yapılan bir araştırmada ya da yatııım kararında uç değerlerin yatırım kararları verilirken dışlanması önemli bir strateji sorunu olarak görülmektedir. Koenker and Bassett (1978) 'in çalışmalarından sonra ampirik çalışmalarda geniş uygulama alanı bulan Kantil Regresyon Yaklaşımı ile EKK arasındaki temel farklııılar bulunmaktadır. EKK analizlerinde tüm gözlem değerlerine eşit ağırlık verilirken, kantil regresyon yaklaşımında bağımlı değişkenin koşullu dağıımındaki farklı noktaları için farklı ağırlıklandırmalar yapılmaktadır. Piyasa modeli açsından, EKK tahmincisinin dikkate almadığı hisse senedi

\footnotetext{
${ }^{5}$ Ayrıntılı bilgi için bkz: Von Neuman ve Morgenstern (1944), Tolga ve Şahin (2009)
} 
getirilerinin uç değerleri için de katsayı hesaplanması mümkün olmaktadır. Bu şekilde farklı getiri düzeylerinde piyasa getirisinin etkisinin, yani finansal beta katsayısının farklılaşması incelenebilmekte ve daha detaylı sonuç alınabilmesi sağlanmaktadır.

Bu çalışmanın amacı, Kantil Regresyon tekniğini panel veriye uygulayarak, 2011-2015 dönemi için Borsa istanbul ve New York Borsası'nda işlem görmüş hisselerin getirileri ile dağılımın farklı noktaları için finansal beta katsayısında meydana gelen değişimleri araştırmaktadır. Bu amaçla, Borsa İstanbul Ulusal 100 endeksinde işlem gören 82 hisse senedinin ve New York Borsası S\&P100 Endeksinde işlem gören 93 hisse senedinin 04.01.2011 31.12.2015 periyodunda meydana gelen günlük getirileri Bloomberg Terminal Uygulaması aracılığı ile panel veri olarak hazırlanmıştır. Veri setinde Borsa İstanbul gelişmekte olan bir piyasayı temsil ederken, New York Borsası gelişmiş bir piyasayı temsil etmektedir. Analizlerden elde edilen sonuçlar iki sermaye piyasası açısından tartışılmıştır.

Çalışma amacı doğrultusunda öncelikle serilerin durağanlıkları incelenmiş ve yatay kesit bağımlılı̆̆ını dikkate alan ikinci nesil panel birim kök test istatistikleri hesaplanmıştır. Yapılan hesaplamalar sonucunda tüm seriler birinci mertebeden durağan olarak tespit edilmiştir. Bir sonraki aşamada panel kantil regresyon tahminleri gerçekleştirilmiştir. Borsa İstanbul için yapılan tahminlerde, incelenen dönem için finansal beta katsayısı, EKK tahmincisi ile elde edilen katsayıya göre hisse senetlerinin yüksek getiri seviyelerinde daha düşük olarak hesaplanmıştır. Hisse senetlerinin düşük getiri seviyelerinde ise EKK tahmincisine göre daha yüksek bir değer aldığı görülmüştür. Analizler, yatırımcıların EKK tahmincileri kullanarak oluşturacakları stratejilerde hata ve kayıplarla karşılaşabileceğini göstermektedir. Ayrıca elde edilen bulgular Borsa İstanbul açısından asimetrik bilgi durumunun olabileceğini göstermektedir. New York Borsası açısından yapılan tahminlerde, incelenen dönem için finansal beta katsayısının farklı getiri seviyeleri için farklı sonuçlar verdiği gözlenmektedir. EKK tahmincisinden elde edilen \%50'lik kantile göre düşük ve yüksek getiri seviyelerinde finansal beta katsayısının arttığı görülmektedir. Bu sonuç, New York Borsası açısından EKK tahmincisi ile elde edilen katsayıların hisse senetlerinin düşük ve yüksek getiri dönemlerinde geçerliliğini kaybettiğini açıkça göstermektedir. Yatııımcıların EKK tahmincisinden elde edilen finansal beta katsayısına göre hareket etmesi durumunda stratejik hatalarla ve kayıplarla karşılaşabileceği düşünülmektedir.

Araştırma bulguları, "Beklenti Teorisi" ve "Beklenen Değer Hipotezi" ışığında değerlendirildiğinde ise iki farklı piyasadaki yatıımcı psikolojileri hakkında da önemli çıkarımlar içermektedir. Tahmin sonuçları, Borsa İstanbul yatırımcılarının yüksek getiri dönemlerinde oluşan iyimser hava nedeniyle kazançlara odaklandığını ve fiyatlamalarda sistematik riski olması gereken seviyeden daha düşük belirlediğini göstermektedir. Bu nedenle \%75'lik kantilde finansal beta EKK katsayılarına göre azalmaktadır. Aksi durumda ise, yatırımcılar kötümser piyasa psikolojisi ile getirilere değil sistematik riske odaklanmakta ve finansal beta katsayısı diğer kantillere göre artmaktadır. New York Borsası yatırımcılarının ise, rasyonel bir şekilde getirilerin beklenen değerin dışında çıktı̆̆ı düşük ve yüksek kantillerde, kötümser piyasa psikolojisine bürünerek sistemik riske odaklandığı tespit edilmiştir. Bu etki dolayısıyla $\% 25$ ve $\% 75^{\prime}$ lik kantillerde finansal betada artış meydana geldiği görülmektedir. Beklenen değerin gerçekleşmesi yani \%50'lik kantilde ise iyimser havanın oluştuğu ve yatırımcların sistematik riske olan hassasiyetlerinin azaldığı tespit edilmektedir. Bu nedenle finansal beta katsayısı azalmaktadır.

\section{REFERENCES}

Allen, D. E. \& Singh, A. K. (2009). Minimizing Loss at Times of Financial Crisis: Quantile Regression as a Tool for Portfolio Investment Decisions. School of Accounting, Finance and Economics \& FEMARC Working Paper Series, No: 0912.

Allen, D. E., Gerrans, P., Singh, A. K. \& Powell, P. (2009). Quantile regression: its application in investment analysis. The Finsia Journal of Applied Finance, Issue: 4.

Barnes, M. L. \& Huges, A. W. (2002). A Quantile Regression Analysis of the Cross Section of Stock Market Returns. Federal Reserve Bank of Boston in its series Working Papers with number 02-2.

Breusch, T.S. \& Pagan, A.R. (1980). The Lagrange Multiplier Test and Its Applications to Model Specification in Econometrics. Review of Economic Studies, 47, 239-253. 
Chang, M. C., Hung, J-C. \& Nieh, C-C. (2011). Reexamination of capital asset pricing model (CAPM): An application of quantile regression. African Journal of Business Management, Vol. 5(33), pp. 12684-12690.

Cohen, K.J., Pogue, J.A. (1967). An Empirical Evaluation of Alternative Portfolio Selection Models, Journal of Business, vol.40, no. 2 (April):166-193.

Elton, E.J. \& Gruber M.J. (1973). Estimating the Dependence Structure of Share Prices, Journal of Finance, vol. 28 , no. 5 (December):120332.

Fama, E. F. \& French, K. R., (1996). Multi-Factor Explanations of Asset Pricing Anomalies. Journal of Finance, 51: 55-84.

Irmak, S. \& Çetin K. (2009). Hisse Senetlerinin Korelasyon Uzaklıklarına Dayalı Olarak Kümelenmesi. Süleyman Demirel Üniversitesi iktisadi ve Idari Bilimler Fakültesi Dergisi, C.14, S.1 s.395-406.

Kahneman, D., \& Tvertsky, A., (1979). Prospect Theory: An Analysis of Decision Under Risk. Econometrica, 47: 2, $263-291$.

Koenker R., Bassett, G. Jr. (1978). Regression Quantiles. Econometrica, 46(1), pp.33-50.

Koenker, R. (2004). Quantile regression for longitudinal data. Journal of Multivariate Analysis 91, pp.74-89.

Küden, M. (2014). Davranışsal Finans Açısından Bireysel Yatırım Tercihlerinin Değerlendirilmesi. Yayımlanmış Yüksek Lisans Tezi, İzmir.

Li, T., Sun, L. \& Zou, L. (2009). State ownership and corporate performance: A quantile regression analysis of Chinese listed companies. China Economic Review, 20: 703-716.

Lintner, J. (1965). The Valuation of Risk Assets and the Selection of Risky Investments in Stock Portfolios and Capital Budgets, Review of Economics and Statistics, vol. 47, no. 1 (February):13-37.

Ma, L. \& Polhman, L. (2008). Return Forecasts and Optimal Portfolio Construction: A Quantile Regression Approach. The European Journal of Finance, $14: 5,409-425$.

Markowitz, H. (1952). Portfolio Selection, Journal of Finance, 7(1), pp.77-91.

Mossin, J. (1966). Equilibrium in a Capital Asset Market, Econometrica, ol. 35, no. 4 (October):768-783.

Pesaran, M. H. (2004). General Diagnostic Tests for Cross Section Dependence in Panels. University of Cambridge, Faculty of Economics, Cambridge Working Papers in Economics No. 0435.

Pesaran, M. H. (2007). A Simple Panel Unit Root Test in the Presence of Cross Section Dependence. Journal of Applied Econometrics, 22(2), pp.265-312.

Roll, R. \& Ross, S. A., (1980). An Empirical Investigation of the Arbitrage Pricing Theory. Journal of Finance, 35: 1073-1103.

Rosenberg, B. (1974). Extra-Market Components of Covariance in Security Returns, Journal of Financial and Quantitative Analysis, Vol. 9 , No. 2 (March):263-273.

Ross, S. A. (1976). The Arbitrage Theory of Capital Asset Pricing. Journal of Economic Theory, 13, pp. 341-360.

Schoemaker, P., J., H., (1982). The Expected Utility Model: Its Variants, Purposes, Evidences and Limitations. Journal of Economic Literature, 20: 2, 529-563.

Sharpe, W. F. (1963). A Simplified Model for Portfolio Analysis. Management Science, Vol. 9, No. 2 (January):277-293.

Sharpe, W. F. (1964). Capital Asset Prices: A Theory of Market Equilibrium under Conditions of Risk. The Journal of Finance, Vol. 19, No. 3, pp. 425-442.

Sharpe, W. F., Alexander, G. J. \& Bailey, J. V. (1999). Invesments. Prentice-Hall, USA.

Taylor, M. \& Sarno, L. (1998). The Behaviour Of Real Exchange Rates During The Post-Bretton Woods Period. Journal of International Economics, 46, 281-312.

Tobin, J. (1958). Liquidity Preference as Behavior towards Risk, Review of Economic Studies, vol. 25, no. 1 (February):65-86.

Tolga, A. \& Şahin, I. (2009). Belirsizlik Altında Karar Alma: Geleneksel ve Modern Yaklaşımlar. Türkiye Ekonomi Kurumu Tartışma Metni, No: 2009/7.

Uyar (2015). Finansal Raporlama Standartları́nın Piyasa Değerini Açıklama Gücü Üzerine Etkisi. Pamukkale Üniversitesi, Sosyal Bilimler Enstitüsü, Yayımlanmamış Doktora Tezi, Denizli.

Von Neuman, J. \& Morgenstein, O. (1944). Theory of Games and Economic Behavior. Princeton Princeton University Press, USA. 